\title{
Modeling and Simulation of Multi-Room Buildings
}

\author{
D.W.U. Perera N.-O Skeie
}

Faculty of Technology, University College of Southeast Norway, Postboks 203, N-3901, Porsgrunn, Norway. E-mail: wathsala.perera@hit.no

\begin{abstract}
Buildings are one of the largest energy consumers in the world which accounts for nearly $40 \%$ of the total global energy consumption. In the countries where cold climate conditions predominate, space heating is the key contributor to the increased energy consumption. Today there is a growing trend to use Building Energy Management Systems (BEMS) to control the energy consumption of buildings in an efficient manner. BEMS require a good heating model of the building to be integrated for better control purposes. This article refers to the development of different types of physics based buillding heating models, regarding single-zone, multi-floor and multi-room buildings. They address the propriety of each model in building heating control concerning the prediction accuracy and the prediction time. These models are verified for a residential building having three floors. According to the results, the multi-floor model is recognized to have the best qualifications obliged as a model for control.
\end{abstract}

Keywords: Multi-floor, Multi-room, Physical models, Single-zone

\section{Introduction}

The building sector is the largest energy end-use sector, followed by transport and industry. Nearly $41 \%$ of the total final energy consumption in Europe was attributed by the building sector in 2010 (EU, 2013). It also accounts for $36 \%$ of the European Union (EU) $\mathrm{CO}_{2}$ emissions (EU, 2013). The average energy consumption of the building sector in the EU has grown by around $1 \%$ per year since 1990, and it has reached $220 \mathrm{kWh} / \mathrm{m}^{2}$ in 2009 (EU, 2013). In Europe, approximately $80 \%$ of the existing buildings are constructed prior to 1990 and out of that $50 \%$ are built before 1960 (EU, 2013). Accordingly, energy savings in the building sector is widely recognized through the refurbishment of the existing buildings considering building envelope and thermal insulation, space heating/cooling, domestic hot water production, ventilation systems and lighting (Paulou et al., 2014). Consequently, a major and sustained energy consumption reduction of buildings is needed for EU to meet its energy objectives and decarbonization agenda. Energy Performance of
Buildings Directive (EBPD) is the main EU policy instrument to enhance the energy performance of buildings via different policies and regulations. Recent recast of EBPD states that all new buildings in the member states must be close to zero energy in 2020 while increasing the energy efficiency in existing buildings (EBPD, 2010).

Northern European countries experience cold climate conditions during one-third of the year. Because of that, space heating claims the single largest energy demand for buildings in those countries. For example, in 2010, final energy consumption of the Norwegian building sector was 308 PJ, and nearly $60 \%$ of that belonged to residential buildings (IEA, 2011). Therefore, many European countries have imposed their own building codes associated with the EU specifications to improve the energy use.

Reduction of energy consumption of a building is a complex process that has to take weather conditions, ventilation, solar irradiation, availability of heating equipment, lighting, the efficiency of equipment, hot water production, and building properties into con- 
sideration. To obtain an optimum energy performance, it is essential to integrate the impacts from each and every fact stated above. A good way to control them is building energy management systems (BEMS). BEMS are a rapidly expanding technology, and they have gained awareness as a standard way of controlling the buildings compared to classical techniques such as thermostat control (Virk et al., 1991). On/Off control, PID control and optimum start-stop routines are the control algorithms used by the current BEMS (Virk et al., 1991). Use of such classical control algorithms may not be the best solution to achieve a higher efficiency via BEMS. Instead, use of an advanced control mechanism with a combined mathematical model of a building has the possibility to address most of the insufficiencies present in the prevailing system (Virk et al., 1991). The heat dynamics of a building has a multi-variable behavior owing to the thermal interactions between the different zones and the Heating, ventilation and air conditioning (HVAC) system (Perera et al., 2014b). Classical controllers have deficiencies in handling such multivariable systems because they are not easy or even impossible to tune for Multiple Input - Multiple Output (MIMO) systems. Accordingly, use of an advanced control methodology with a mathematical model of the building has a higher likelihood of delivering improved performance with fewer setpoint deviations. Thus, it is crucial to develop a good quality building heating model to produce a favorable outcome by BEMS.

There are three general classifications of building heating models available for control purposes: (i) white box models; (ii) black box models; and (iii) grey box models. Further information about the building heating model categories can be found in Foucquier et al. (2013), Kramer et al. (2012), Spindler and Norford (2009) and Zhao and Magouls (2012). White box building heating models are developed based on the physical principles of mass, energy and momentum transfer. They consist of several equations with numerous coefficients to describe the building geometry, thermal and physical properties of the building envelope and equipment. A large number of numerical software tools are available for solving such systems. However, still there are some deficiencies present in solving such systems when it comes to the calibration of physical parameters based on the experimental data. Software tools such as Energy Plus, TRNSYS, ESP-r, Fluent, and DOE-2 produce highly accurate comprehensive mechanistic building heating models. Even though, they are quite accurate they may have a high computational burden with a delayed response that makes them not suitable for real-time applications. For example, in order to use a CFD model for on-line control, it should be simplified to a lower order representation (Yao et al., 2013). There are also more generic programs developed in tools such as MATLAB/SIMULINK, C, C\#, Java, Phyton and Modelica, which can be used for building simulation. These models can be implemented according to the user requirements and are also easy to apply in control applications. However, the selection of a physical model for a BEMS is a balance between the model complexity, and the desired accuracy (Lu et al., 2009).

A black box building model is developed for a particular building based solely on the collected experimental data. These models do not require any physical information of the building, and also, the resulting coefficients do not have any physical meaning. They could be more stable compared to the models developed based on physical approaches, but only valid for the building where the data is collected. For a black box model to be a good fit, a substantial amount of data is needed for identifying parameters because the models do not present the actual mechanisms and parameters of the system.

Grey box models are a blend of white and black box models, and they are widely used for parameter estimation purposes. In building systems, grey models can be used to analyze the building energy behaviour when there is only incomplete or uncertain data. However, only a limited work has been done on grey models when it comes to building systems (Zhao and Magouls, 2012).

The goal is to have a physical building heating model that can estimate the heating time of a building. Heating time is the time to change the temperature from a low setpoint to the comfort setpoint. BEMS can lower the temperature of the building when it is not in use, and the model can be used to estimate the start time of heating system before any occupancy. Therefore, the prediction time of the model is of high importance. The present study focuses on the development of a building heating model using a physical approach which can be applied to multi-room buildings based on the previous work for single-zone and multi-floor models carried out by the same research group (Perera et al., 2014b), (Perera et al., 2014a). The model will include ventilation, internal air flows, the presence of humidity, heat recovery, solar irradiation, heat capacity of furniture and thermal mass of the building envelope. The extension procedure of the single-zone model to a multi-floor and multi-room buildings will be presented. A comparison of each model is presented concerning the feasibility of applying them in on-line building control in BEMS regarding prediction accuracy and prediction time. 


\subsection{Previous work}

There are a large number of research articles published regarding the development of building models in the recent past. Most of them use proprietary software tools specifically developed for building simulations, and these models are not explicit. Hence, they cannot be integrated with open architectural systems, and some models are too complex for on-line control. We here present the explicit physical models addressing the possibility of extending for multi-zone buildings which are also implemented in more general simulation tools like MATLAB.

A single-zone model for a whole building based on a general methodology using the first principles is presented in (Lu et al., 2014). Energy balance for indoor air (including ventilation heat losses) and the thermal mass of the building envelope (walls, the roof, the floor, windows and the doors) have been addressed. Each envelope component is modeled as an n-layer composite slab having constant thermal conductivity, diffusivity and density for each layer assuming one-dimensional geometry. Mass balance equation is not included in the model. The presented method is also application independent and can be applied to almost any type of building problem. The model assessment has shown good agreement with the measurements, and the model is efficient. Authors suggest that the model can be applied in control applications. However, the model is only validated for a single-zone and not applied for multi-zone buildings.

A simple dynamic model to simulate heating and cooling energy consumption in buildings is presented in (Rosa et al., 2014). A lumped capacitance approach combined with the electrical analogy has been used in the model development and is implemented in Matlab/SIMULINK platform. The transient energy balance equations for internal air and external walls are used, and climatic data such as external temperatures, solar irradiation, and wind speed has been used. The results are validated by comparison with the outcomes of TRNSYS and Energy Plus. The authors do not discuss the possibility of application of the model in multi-zone building applications.

A resistance and capacitance based building model with a door-open model has been presented in (Lin et al., 2012). Initially, a single-zone control-oriented model is developed for commercial buildings, and it is stated that model is composable, i.e. the models of adjacent rooms can easily be connected to each other to compose a multi-zone model. The heat transfer through external and internal building envelope, heat convection with outside air through HVAC system, solar irradiation, heat gain from occupants and equipment are addressed in the study while ventilation is not addressed.

Yao et al. (2013) have presented a dynamic statespace model for a single room after dividing it into three separate zones. Both indoor temperature and humidity have been taken into consideration. However, the model is validated only for a short period (2400 sec), and the results are within $12 \%$ average error.

A physical modeling approach for Single Input - Single Output (SISO) system is demonstrated by Desta et al. (Desta et al., 2005). They present that the developed methodology has immense practical importance when reduced order models are required for control purposes. The model addresses the forced convection heat transfer phenomena in ventilation systems and authors have mentioned that the model can be upgraded to MIMO systems.

Khoury et al. (2005) have developed a multi-zone building model in Matlab/Simulink environment, and they have used the SIMBAD Building and HVAC Toolbox, which provides ready to use HVAC model and related utilities. The model is developed with a graphical interface "SIMBDI" to draw the building and to enter the data interactively. An air zone model, wall model, window model, infrared heat exchange, and solar radiation are incorporated into the model. The validations are carried out for a two zone building for seven days, and the results are in good agreement with the TRNSYS simulation. However, in the model validation, ventilation, inter-zone air flow, internal gains and equipment power are set to zero.

In Mendes et al. (2003), a building temperature performance analysis with automatic control has been addressed in MATLAB environment. The models are described in terms of state-space variables with a lumped approach. Indoor air, building envelope and oil heater dynamics are presented with energy balance equations and the mass balance for water vapor is included.

The models presented above do not provide total mass balance equations to represent the ventilation. Some are included with the mass balance for water vapor only. Modeling of internal thermal mass is also not given much attention in most of the available white box models. Further, validation of the models for singlezone buildings rather than multi-floor or multi-room buildings is given. Articles which express the modeling of multi-floor or multi-room buildings for control purpose were not found. Few articles have stated that their models can be used in control applications. However, none of them has mentioned the prediction time for simulations which makes it difficult to evaluate the possibility of applying them in on-line building control.

The rest of the paper is arranged to present the physical model development procedure, description of the test building, results from developed models, analysis 
of the model predictions and ultimately the concluding remarks.

\section{Modeling Approach}

In this section, a dynamic heating model for a multizone building unit is presented. Figure 1 represents the building unit components such as walls, furniture, heaters, appliances, doors, windows, floors, ceiling/roof, solar irradiation and the air movements. Each and every component shown is important in determining the thermal dynamics of buildings in different ways. Heat transfer processes incorporated into a building could be owing to all the conduction, convection, and radiation mechanisms. Conduction heat transfer process associated with buildings is often multi-dimensional and transient. Finite different or finite element analysis can solve such problems. Exterior wall and roof conduction, interior mass conduction (interior walls, interior floors, furniture) and ground heat loss are some examples of conduction heat transfer applications. The convection mechanisms involve with the heat transfer at exterior and interior surfaces, inter and intra-space air motion and heat transfer within the window glass panes. Convection method of heat transfer is governed by the convective heat transfer coefficient, and it is influenced by the nature of the air boundary layer and the surface geometry. Electromagnetic waves traveling through space are called the radiation, and when these waves hit an object they transfer heat. Both short wavelength and long wavelength radiation types are included in the building heat transfer processes. Short wavelength radiation includes: solar heat absorption on opaque exterior surfaces; solar heat transmission through transparent surfaces; solar heat absorption and reflection by internal building surfaces; and absorption and reflection of solar heat by window glasses (Kusuda, 1977). Heat emission by exterior surfaces to the sky, heat exchange among internal surfaces, heat exchange between interior surfaces and occupants are some examples of long wavelength heat transfer (Kusuda, 1977).

In this work, all heat transfer phenomena mentioned above are not taken into consideration. Instead, the most influential factors that can determine the thermal performance of buildings will be addressed. Those factors will be discussed with the appropriate equations henceforth.

Air exchange with outside environment is one of the fundamental necessities in closed buildings to achieve thermal comfort and health of the occupants. It plays a crucial role in the convective mode of heat transfer in buildings. If the building is provided with higher amounts of ventilation, more energy must be supplied

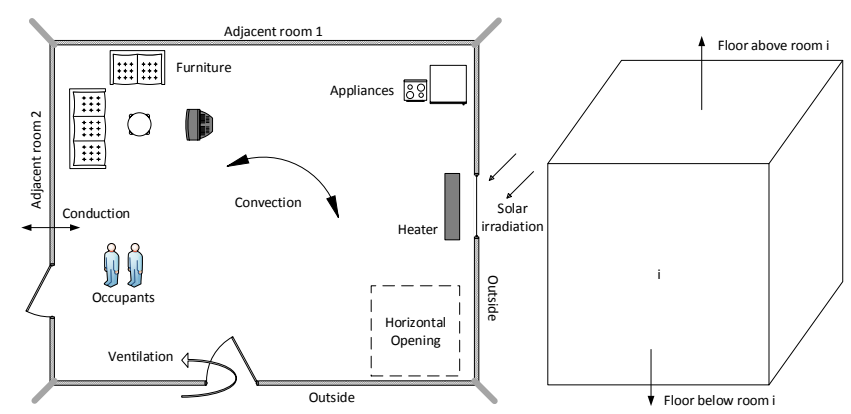

Figure 1: Configuration of the building unit.

to raise the temperature of the incoming air to achieve the thermal comfort. Simultaneously, when an adequate amount of air is not provided, the air quality will be affected. Therefore, there is a compromise between the air quality and the thermal comfort when it comes to energy savings. Hence, to determine the temperatures and heating loads of buildings accurately, the application of mass balances for the ventilated spaces is essential. The mass balance equation for the building unit given in figure 1 can be expressed as in equation (1). Here, the subscript " $i$ " denotes interested building unit while subscript " $j "$ denotes the building unit adjacent to the unit represented by " $i$ ". " $n$ " is the number of neighbouring rooms to room i. Description of the symbols is given under the Nomenclature.

$$
\begin{gathered}
\dot{m}_{\infty, i}-\dot{m}_{i, \infty}+\sum_{j=1}^{n} \dot{m}_{j, i}^{v}- \\
\frac{d \rho_{i}}{d t}=\frac{\sum_{j=1}^{n} \dot{m}_{i, j}^{v}+\sum_{j=1}^{n} \dot{m}_{j, i}-\sum_{j=1}^{n} \dot{m}_{i, j}}{V_{i}}
\end{gathered}
$$

In the above equation, $\dot{m}^{v}$ and $\dot{m}^{h}$ represent the air exchange between two floors and two rooms. Determination of this mass flow is a fairly complicated process. These air flow rates depend on the density difference and pressure difference between the two spaces. However, the pressure difference between two zones in the same building is small and difficult to measure accurately. Therefore, the estimation of the air exchange rates is quite challenging. In Peppes et al. (2002), a method has been developed to estimate the buoyancy-driven air flow along a stairwell assuming one-dimensional flow. This formula can be used to calculate the air exchange between two floors connected by a stairwell. It has been used in Perera et al. (2014b) to assess the air mixing in between floors of a three-floor residential building after some simplifications. However, when it comes to the simulation of large buildings with several zones, the application of this equation may provide unstabilized results. Hence, 
the model should first be tested with equation (2) and if the results are not satisfactory, simplifications to equation (2) can be done.

$$
\dot{m}^{v}=\rho A_{o} C_{d}\left[\frac{\Delta T g H}{T}\right]^{0.5}
$$

Several researchers have developed different formulas for determining the air flow rate across vertical openings of the buildings (Brown and Solvason, 1962), (Allard et al., 1992), (Allard and Utsumi, 1992), (Riffat, 1991). This flow is bi-directional and hence complex to be solved using simple codes. Computational fluid dynamics softwares are required to obtain better solutions for such problems. If the model is too complicated and if it requires a longer time to provide a solution, it can no longer be applied to on-line control. Because of that, in this study, air exchanges along the doorways (horizontal air exchanges) are ignored by using simplification strategies.

The general energy balance equation for the building unit is derived combining the standard energy balance equation, the relations $E=I+P V, d E=d\left(m \widehat{c}_{p} T\right)$ and the ideal gas law $P V=n R T$. The equation takes the convection heat flows, conduction heat flows and radiation heat flows into consideration.

$$
\begin{gathered}
\dot{m}_{\infty, i} \widehat{h}_{\infty}-\dot{m}_{i, \infty} \widehat{h}_{i}+\dot{Q}_{i} \\
+\sum_{j=1}^{n} \dot{m}_{j, i} \widehat{h}_{j}-\sum_{j=1}^{n} \dot{m}_{i, j} \widehat{h}_{i} \\
\frac{d T_{i}}{d t}=\frac{+\sum_{j=1}^{n} \dot{m}_{j, i} \widehat{h}_{j}-\sum_{j=1}^{n} \dot{m}_{i, j} \widehat{h}_{i}}{\rho_{i} V_{i}\left(\widehat{c}_{p_{i}}-R / M_{i}\right)}-\frac{T_{i}}{\rho_{i}} \frac{d \rho_{i}}{d t}
\end{gathered}
$$

The term $Q_{i}$ represents the net heat flow to the building unit, and it can be approximated using equation (4). The heat supply from heaters, solar irradiation, and household applications are taken into consideration. The heat losses addressed in the model are owing to the walls, floor, ceiling/roof, windows, doors, and furniture. In order to determine the heat losses through various components of the building, equation (5) can be used.

$$
\begin{aligned}
& \begin{aligned}
\dot{Q}_{i}= & Q_{\text {heater }}+Q_{\text {solar }}+Q_{\text {appliances }}-\dot{Q}_{w} \\
& \dot{Q}_{f}-\dot{Q}_{c}-\dot{Q}_{\text {window }}-\dot{Q}_{\text {door }}-\dot{Q}_{\text {fur }}
\end{aligned} \\
& \dot{Q}=U A \Delta T
\end{aligned}
$$

The heaters in the building are assumed to have $100 \%$ efficiency in heating. Heat supplied by the solar irradiation has to be determined based on the measured solar irradiation profile. The solar radiation that is transmitted through the transparent windows of the building is only considered. The radiation heat absorbed by the building envelope is not counted. The transmitted solar irradiation heats the air inside the building depending on the absorptivity of the air. Higher amounts of carbon dioxide and water vapor in the air may absorb more heat. Household appliances such as refrigerators, personal computers, light bulbs and televisions emit some amount of heat during their operation. This heat also contributes to heat up the building, which is incorporated into the model.

The heat losses through the building envelope can be estimated using equation (5). In addition to that, the thermal dynamics of these components must be integrated with the model to have better performance. It is essential to do so as the thermal mass of such components have a significant contribution to the temperature fluctuations inside the building. Walls, floor, and ceilings/roof usually consist of several layers of dissimilar materials such as wood, concrete, and insulation. Throughout this study, all the layers are consolidated into one element having uniform thermal properties for simplicity. Transient heat equation $\left(\frac{\partial T}{d t}-\alpha \nabla^{2} T-\frac{\dot{q}}{\rho \widehat{c}_{p}}=0\right)$ is discretized using the finite difference method to obtain the respective energy balance equations for the walls, floor, intermediate floors and roof of the building unit assuming only one-dimensional heat transfer. There is no heat generation inside the walls and roof. The deduced ordinary differential equations are given below.

$$
\begin{gathered}
\frac{d T_{w}}{d t}=\alpha_{w}\left[\frac{T_{w, i}^{s}-2 T_{w}+T_{w, j}^{s}}{\left(x_{w} / 2\right)^{2}}\right] \\
\frac{d T_{r}}{d t}=\alpha_{r}\left[\frac{T_{r, i}^{s}-2 T_{r}+T_{r, j}^{s}}{\left(x_{r} / 2\right)^{2}}\right] \\
\frac{d T_{f}}{d t}=\alpha_{f}\left[\frac{T_{f, i}^{s}-2 T_{f}+T_{f, g}^{s}}{\left(x_{f} / 2\right)^{2}}\right]+\frac{\dot{q_{f}}}{\rho_{f} \widehat{c}_{p_{f}}} \\
\frac{d T_{i f}}{d t}=\alpha_{i f}\left[\frac{T_{i f, i}^{s}-2 T_{i f}+T_{i f, g}^{s}}{\left(x_{i f} / 2\right)^{2}}\right]+\frac{\dot{q_{i f}}}{\rho_{i f} \widehat{c}_{p_{i f}}}
\end{gathered}
$$

The thermal mass of household furniture also plays an important role in building heating. They can act either as a heat sink or heat source depending on the positive or negative temperature difference with the surroundings. Availability of the furniture inside a building prolongs the time required to heat up the air inside the room. Concurrently, it takes a longer time to cool down the building as the heat release from the furniture is slow. To simplify the modeling of heat transfer in furniture, all the furniture with different properties are aggregated into a single 
large spherical object having equivalent average thermal diffusivity. Heat equation in spherical coordinates $\left(r^{2} \frac{\partial T}{\partial t}-\alpha \frac{\partial}{\partial r}\left(r^{2} \frac{\partial T}{\partial r}\right)-r^{2} \frac{\dot{q}}{\rho \widehat{c}_{p}}=0\right)$ is discretized to obtain the representative energy balance equation for the furniture (equation 10).

$$
\frac{d T_{f u r}}{d t}=\frac{\alpha_{f u r}}{(r / 2)^{2}}\left[3 T_{f u r, i}{ }^{s}-2 T_{\text {fur }}-T_{\text {fur }, \text { centre }}\right]
$$

\section{The test building}

This section outlines the main features of the test building which is a three-storeyed residential building built in 1987 and located in the south part of Norway. The building has three storeys: (i) attic; (ii) main floor; and (iii) basement.

The dimensions of the building with the dimensions of the windows and doors are displayed in figure 2 . The heights of the main floor and basement are $240 \mathrm{~cm}$ and $235 \mathrm{~cm}$ respectively. The height of the attic is highest along its center line which is equal to $198 \mathrm{~cm}$, and then it gradually diminishes to 0 adjacent to the side walls. The thickness of the roof of the building is nearly $30 \mathrm{~cm}$, and both inner ceilings of the building have a thickness of $30 \mathrm{~cm}$ each. The building is mainly constructed using wood. Though, the most of the walls and the floor of the basement are built using concrete. The concrete ground floor in the basement has a thickness of $20 \mathrm{~cm}$. Mineral wool is applied as an insulation material for walls, intermediate floors, and roof. The locations where the temperature and relative humidity measurements are obtained are shown in figure 2. All inside temperature and relative humidity measurements except for kitchen are collected using EL-USB-2+ data loggers ${ }^{1}$. It has an accuracy of $\pm 0.3^{0} \mathrm{C}$ for temperature and $\pm 2.0 \%$ for relative humidity. The outside and kitchen temperatures and relative humidities are measured using a weather station. A pyranometer is used to estimate the amount of solar irradiation received by the window in the attic. The main floor and the basement of the building are equipped with a mechanical ventilation system, and it is integrated with a heat recovery system of $77 \%$ heat recovery efficiency. The cumulative average air inflow rate into the building is $230 \mathrm{~m}^{3} / \mathrm{hr}$.

There is a $1000 \mathrm{~W}$ heater placed in the attic for heating. In addition, there are four personal computers running all the time which supply thermal energy of 480W. 3300W power is provided by an electrical heater to the main floor of the building. This heater is controlled by an on/off controller to hold the temperature at setpoints assigned by the residents depending on
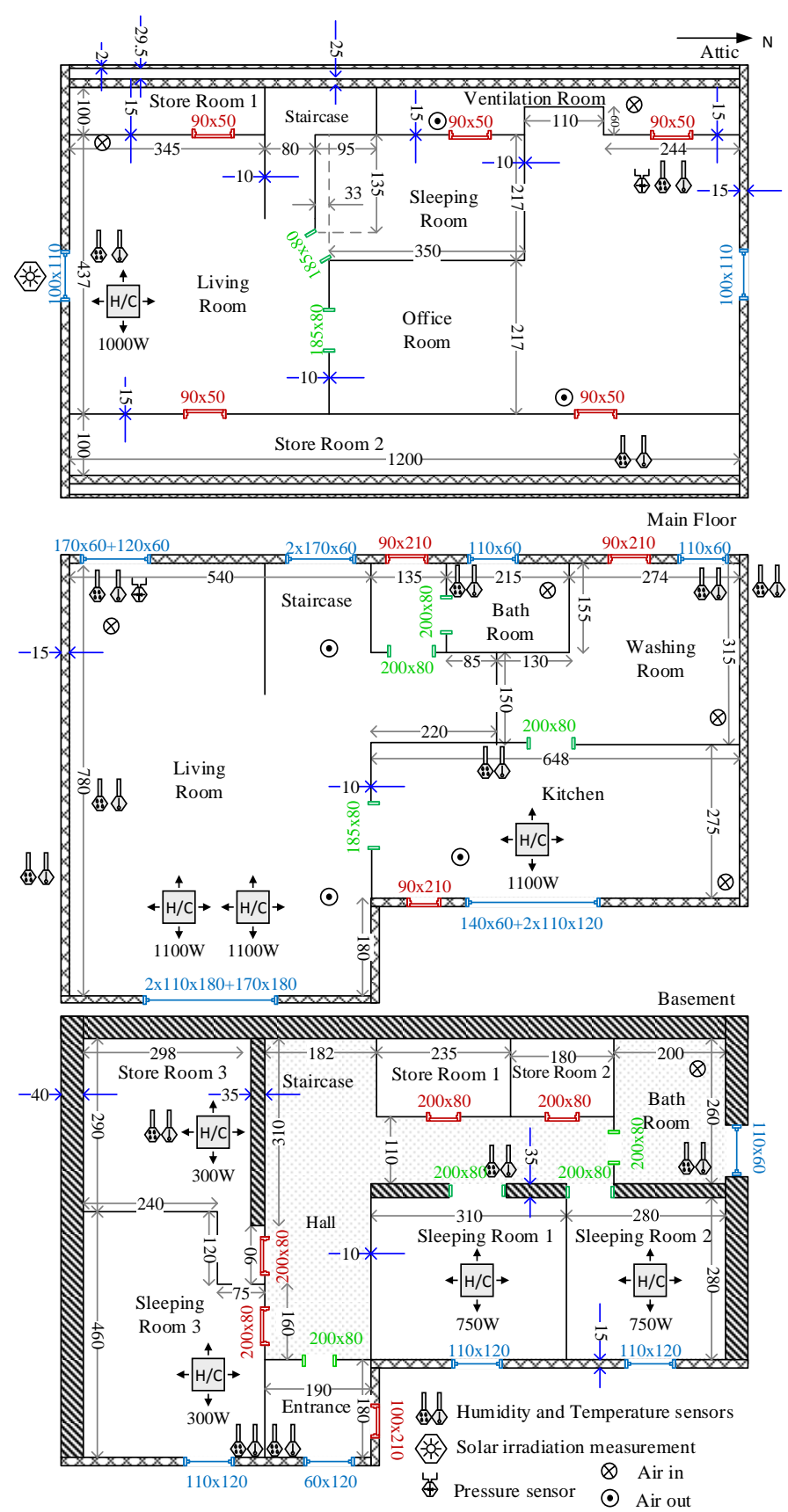

Figure 2: Configuration of the building with dimensions and sensor locations.

${ }^{1}$ http://www.lascarelectronics.com/temperaturedatalogger.php?datalogger =378 
the time of the day. Supplementary to the electrical heater, wood firing is used to heat the building particularly during the cold climate conditions which is not demonstrated in this work. Further, it is assumed that $150 \mathrm{~W}$ of thermal power is released to the main floor by electrical appliances operating inside the building. There are six heaters installed in the basement. Out of that, two are wall heaters of $750 \mathrm{~W}$ that are controlled by an on/off controller and installed in the basement sleeping rooms 1 and 2. In storage room 3 and sleeping room 3 , there are two heaters each $300 \mathrm{~W}$. There are two full-time running floor heaters in the hall and the bathroom which supplies roughly $550 \mathrm{~W}$.

The experiment of the test building is carried out for five days from 00:00 on $12^{\text {th }}$ January to 00:00 on $17^{\text {th }}$ January, 2015. The outside temperature, outside relative humidity and the solar irradiation profiles for the mentioned period are presented in figure 3 .
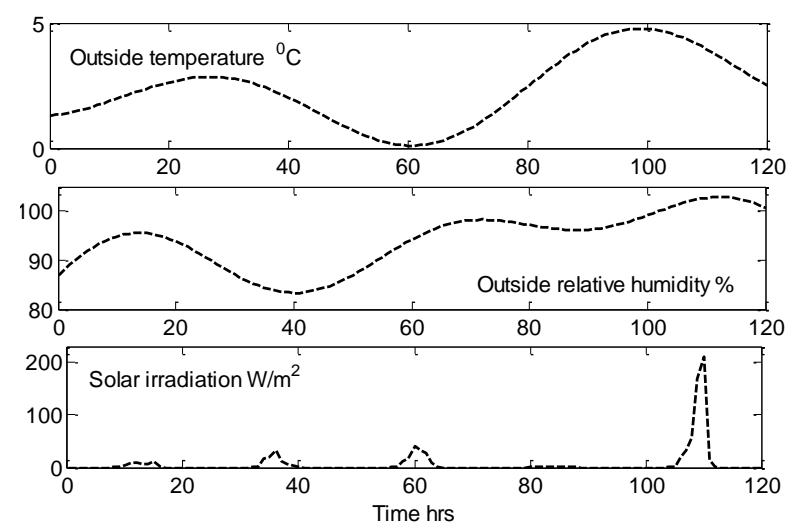

Figure 3: Variation of outside temperature, relative humidity and solar irradiation during the experimental period.

\section{Results}

The aforementioned physical model is implemented in MATLAB and simulated for the three-storeyed residential building. Here, the building is considered and simulated as a single-zone building, multi-floor building and a multi-room building. The outcomes are interpreted based on the applicability of each model in BEMS for controlling the temperature and energy use. All simulations are carried out using MATLAB ode15s solver. When it comes to the parameter estimation of each model, there are challenges linked to the calibration of physical parameters in the models with respect to experimental data. Hence, some parameters may not have a good physical interpretation and the same parameter in different models may have distinct values.

\subsection{Single-zone model}

In the single-zone model, the whole test building with three floors is considered as one unit. Therefore, this model has zero values for the terms that are related to internal air flows $\left(\dot{m}^{v} \dot{m}^{h}\right)$. Further, equation (9) which represents the dynamics of intermediate floors of the building is not combined in this model. The single-zone model consists of six states including the density of air and temperatures of air, walls, roof, floor and furniture. The air temperature of the building is controlled using an on-off controller such that the temperature setpoint is $16^{0} \mathrm{C}$ from $4: 00$ to $8: 00$ and $16.5^{\circ} \mathrm{C}$ from 13:00 to 23:00. The measured temperature is obtained based on the average temperature profile of the building. During the rest of the time, the temperature of the building is set to $10^{\circ} \mathrm{C}$. The model parameters are addressed in Table 1 . The measured and simulated inside temperature variations are presented in figure 4 .

Table 1: Parameter specification for single-zone model

\begin{tabular}{lll}
\hline \multicolumn{2}{l}{ Symbol } & Value \\
\hline$\alpha_{\text {walls }}$ & $\mathrm{m}^{2} / \mathrm{K}$ & $1.25 \mathrm{e}-07$ \\
$\alpha_{\text {roof }}$ & $\mathrm{m}^{2} / \mathrm{K}$ & $4.62 \mathrm{e}-07$ \\
$\alpha_{\text {floor }}$ & $\mathrm{m}^{2} / \mathrm{K}$ & $4.92 \mathrm{e}-07$ \\
$\alpha_{\text {fur }}$ & $\mathrm{m}^{2} / \mathrm{K}$ & $4.44 \mathrm{e}-08$ \\
$U_{\text {walls }}$ & $\mathrm{W} /\left(\mathrm{m}^{2} \mathrm{~K}\right)$ & 0.5 \\
$U_{\text {roof }}$ & $\mathrm{W} /\left(\mathrm{m}^{2} \mathrm{~K}\right)$ & 0.1 \\
$U_{\text {floor }}$ & $\mathrm{W} /\left(\mathrm{m}^{2} \mathrm{~K}\right)$ & 0.1 \\
$U_{\text {fur }}$ & $\mathrm{W} /\left(\mathrm{m}^{2} \mathrm{~K}\right)$ & 0.1 \\
$U_{\text {doors }}$ & $\mathrm{W} /\left(\mathrm{m}^{2} \mathrm{~K}\right)$ & 0.1 \\
$U_{\text {windows }} \mathrm{W} /\left(\mathrm{m}^{2} \mathrm{~K}\right)$ & 0.1 \\
\hline
\end{tabular}

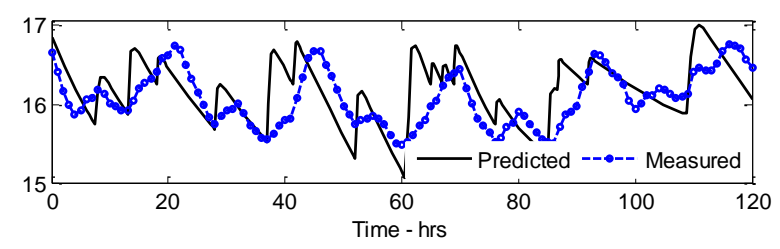

Figure 4: Variation of inside air temperature in the single-zone model $\left[{ }^{0} \mathrm{C}\right]$.

\subsection{Multi-floor model}

Multi-floor model is developed for the building considering each floor as one unit. The model con- 
sists of 16 state variables comprising $\rho_{a i r} \mathrm{x} 3, \mathrm{~T}_{\text {air }} \mathrm{x} 3$, $\mathrm{T}_{\text {wall }} \mathrm{x} 3, \mathrm{~T}_{\text {Groundfloor }}, \mathrm{T}_{\text {Roof }}, \mathrm{T}_{\text {Intermediatefloor } \mathrm{x} 2}$ and $\mathrm{T}_{\text {Furniture }} \mathrm{x} 3$. In this model, horizontal air exchanges $\left(\dot{m}^{h}\right)$ are set to zero. On-off controllers control the air temperature of each floor of the building and the setpoints are given in Table 2. Similar to the previous simulation shown for the single-zone model, the temperature is set to $10^{\circ} \mathrm{C}$ during the uncontrolled periods.

Table 2: Temperature setpoints for each floor of the building based on the time of the day

\begin{tabular}{lll}
\hline Unit & Time & Setpoint \\
\hline Attic & $16: 00-24: 00$ & $19^{0} \mathrm{C}$ \\
Main floor & $4: 00-8: 00$ & $17^{0} \mathrm{C}$ \\
& $13: 00-22: 00$ & $17.5^{0} \mathrm{C}$ \\
Basement & $18: 00-22: 00$ & $15^{0} \mathrm{C}$ \\
\hline
\end{tabular}

The thermal parameters associated with the building enclosure and furniture, which are used in MATLAB simulation are presented in Table 3 .

Table 3: Parameter specification for multi-floor model

\begin{tabular}{lllll}
\hline \multicolumn{2}{l}{ Symbol } & Attic & $\begin{array}{l}\text { Main } \\
\text { floor }\end{array}$ & Basement \\
\hline$\alpha_{\text {walls }}$ & $\mathrm{m}^{2} / \mathrm{K}$ & $1.69 \mathrm{e}-7$ & $1.49 \mathrm{e}-7$ & $1.18 \mathrm{e}-7$ \\
$\alpha_{\text {roof }}$ & $\mathrm{m}^{2} / \mathrm{K}$ & $4.62 \mathrm{e}-7$ & & \\
$\alpha_{\text {floor }}$ & $\mathrm{m}^{2} / \mathrm{K}$ & & & $4.92 \mathrm{e}-7$ \\
$\alpha_{\text {if }}$ & $\mathrm{m}^{2} / \mathrm{K}$ & $1.06 \mathrm{e}-6$ & $1.06 \mathrm{e}-6$ & \\
$\alpha_{\text {fur }}$ & $\mathrm{m}^{2} / \mathrm{K}$ & $4.44 \mathrm{e}-8$ & $4.44 \mathrm{e}-8$ & $4.44 \mathrm{e}-8$ \\
$U_{\text {walls }}$ & $\mathrm{W} /\left(\mathrm{m}^{2} \mathrm{~K}\right)$ & 0.8 & 0.4 & 0.1 \\
$U_{\text {roof }}$ & $\mathrm{W} /\left(\mathrm{m}^{2} \mathrm{~K}\right)$ & 0.3 & & \\
$U_{\text {floor }}$ & $\mathrm{W} /\left(\mathrm{m}^{2} \mathrm{~K}\right)$ & & & 0.1 \\
$U_{\text {if }}$ & $\mathrm{W} /\left(\mathrm{m}^{2} \mathrm{~K}\right)$ & 0.1 & 0.1 & \\
$U_{\text {fur }}$ & $\mathrm{W} /\left(\mathrm{m}^{2} \mathrm{~K}\right)$ & 2 & 2 & 0.9 \\
$U_{\text {doors }}$ & $\mathrm{W} /\left(\mathrm{m}^{2} \mathrm{~K}\right)$ & 0.5 & 0.5 & 0.2 \\
$U_{\text {windows }} \mathrm{W} /\left(\mathrm{m}^{2} \mathrm{~K}\right)$ & 0.4 & 0.4 & 0.2 \\
\hline
\end{tabular}

The simulation of the multi-floor model provides the following predictions for the air temperature of each zone of the building as shown in figure 5 .

\subsection{Multi-room model}

Simulation of the test building using a multi-room model is a complicated task where heat transfer from many different zones in the building needs to be addressed. According to figure 2, there are six rooms in the attic, five rooms in the main floor and nine rooms in the basement. If each room is considered a separate building unit, the model would be very challenging to handle with many states and many differential
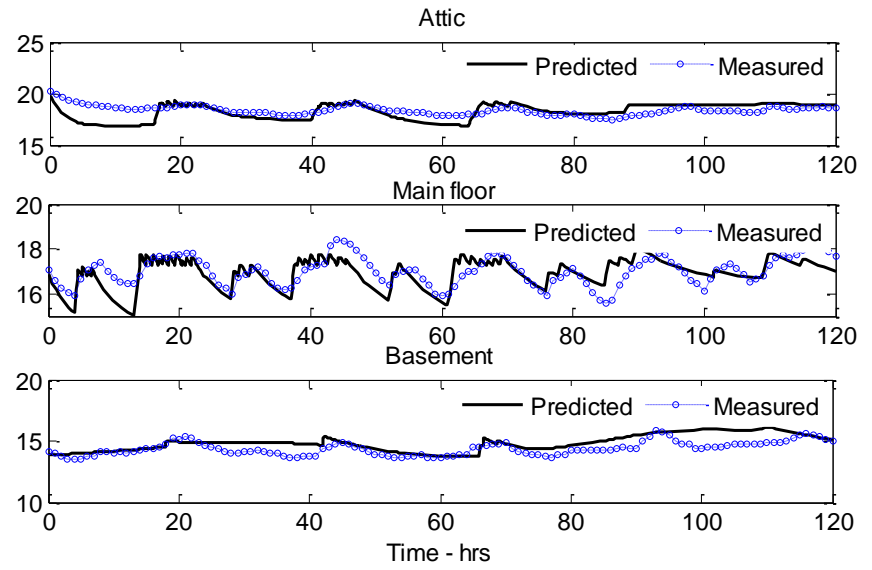

Figure 5: Variation of inside air temperature in the attic, main floor and basement in the multifloor model $\left[{ }^{0} \mathrm{C}\right]$.

equations. Therefore, to avoid the complexities, few simplification approaches are followed:

- The modeling of horizontal air exchanges (equation (1)) across door openings is not simple as modeling of vertical air flows. The available horizontal air flow models are complex, and application of them in the multi-room model makes the model subjected to numerical instabilities and higher prediction times which contradicts the goal of having a simple and fast model to be used in control applications. Hence, the modeling of horizontal air exchanges is neglected by considering the existence of open and closed doors.

- The rooms in a certain floor of a building are regarded as separate units if they have doors which are habitually closed. If the door of room $\mathrm{A}$ is open to room $\mathrm{B}$, both room $\mathrm{A}$ and room $\mathrm{B}$ mutually constitutes one building unit. With that approach, it is not necessary to take the horizontal air movements into account, and only vertical air movements apply. With the above simplification approach, the number of units in the building that should be modeled is diminished.

- In the attic; living room, office room and sleeping room are connected by open doors and hence form one unit. Besides, there are three closed rooms which are comparatively small. Further, these rooms are storage rooms, and individual modeling of them is not so significant. Therefore, the entire attic is viewed as one unit.

- In the main floor, all rooms together constitute one unit owing to the open doors in each room. 
- In the basement, the hall, entrance, bathroom, sleeping room 1 and 2 form one unit (Basement1). As storage room 1 and storage room 2 are small and have no heaters installed they are counted as one unit (Basement-2). Storage room 3 (Basement-3) and sleeping room 3 (Basement-4) are two separate rooms. Therefore, the basement consists of four rooms to be modeled.

- The temperature control of the building is interested in the areas which are regularly occupied. Living and office rooms in the attic, living room and kitchen in the main floor and the hall and sleeping rooms in the basement are highly focused and hence claims good temperature control. For example, the temperature control in the storage rooms is not necessary. Maintaining a temperature above some positive value to avoid freezing of water sources is however expected.

Based on the above simplifications, the number of rooms in the test building is now decreased to six. The multi-room model developed for these six units consists of 28 states. When applying the mass balances, only three differential equations are used to represent the air densities of the entire attic, entire main floor, and the complete basement. The rest of the states cover air temperatures of six zones, furniture temperatures of six zones, temperatures of roof and floor, temperatures of five outside walls and four inside walls and temperatures of two intermediate floors. The controlled temperature setpoints in each unit of the building are presented in Table 4. In Basement-2, there is no heating and hence no temperature control.

Table 4: Temperature setpoints for each unit of the building based on the time of the day

\begin{tabular}{lll}
\hline Unit & Time & Setpoint \\
\hline Attic & $16: 00-24: 00$ & $19^{0} \mathrm{C}$ \\
Main floor & $4: 00-8: 00$ & $17^{0} \mathrm{C}$ \\
& $13: 00-22: 00$ & $17.5^{0} \mathrm{C}$ \\
Basement-1 & $5: 00-7: 00$ & $15.5^{0} \mathrm{C}$ \\
& $12: 00-22: 00$ & $15.5^{0} \mathrm{C}$ \\
Basement-3 & $4: 00-9: 00$ & $15^{0} \mathrm{C}$ \\
& $9: 00-16: 00$ & $14.5^{0} \mathrm{C}$ \\
& $18: 00-24: 00$ & $15^{0} \mathrm{C}$ \\
Basement-4 & $16: 00-24: 00$ & $16.5^{0} \mathrm{C}$ \\
\hline
\end{tabular}

The thermal parameters of the multi-room model are shown in Table 5 and Table 6 . The overall heat transfer coefficient associated with all windows are 0.4 , and it is 0.5 for all doors.
The air temperature predictions of each room are presented in figure 6 and 7 .
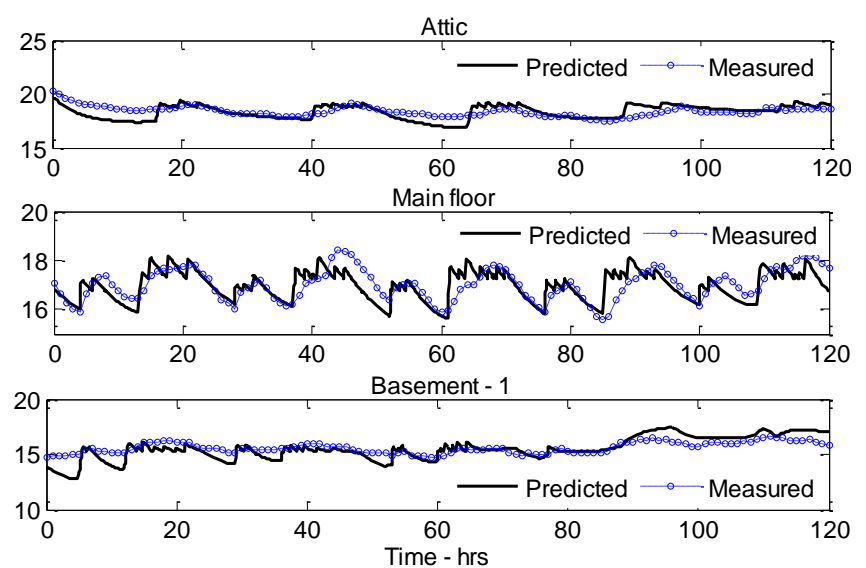

Figure 6: Variation of inside air temperature in the attic, main floor and basement-1 in the multiroom model $\left[{ }^{0} \mathrm{C}\right]$.
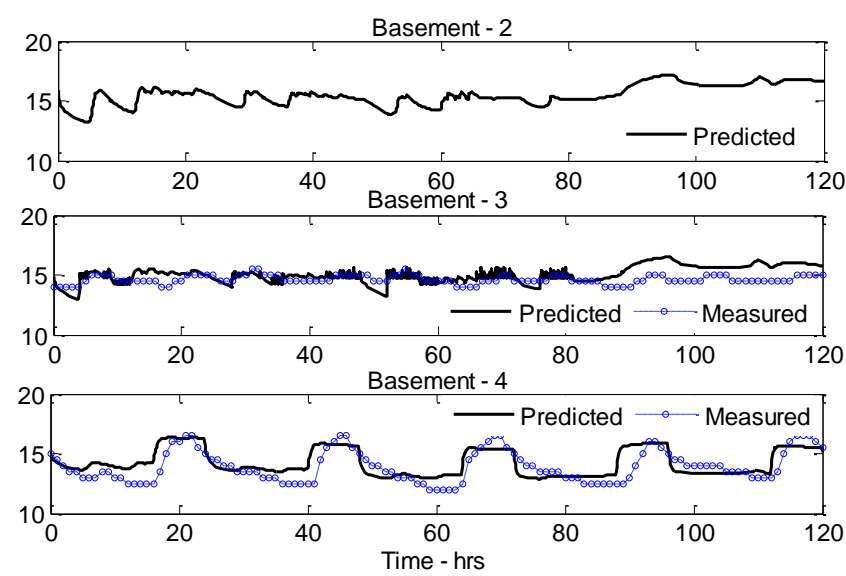

Figure 7: Variation of inside air temperature in the basement-1, basement- 2 and basement- 3 in the multi-room model $\left[{ }^{0} \mathrm{C}\right]$.

\section{Discussion}

The performance of each model is described in this section based on the results obtained for the test building simulations.

The results from the single-zone model are not as reliable as the predictions from the other models. There are significant deviations in the predictions from the 
Table 5: Parameter specification in the multi-room model - Thermal diffiusivity $\left[\mathrm{m}^{2} / \mathrm{K}\right]$

\begin{tabular}{lllll}
\hline Attic & $\alpha_{\text {walls }}$ & $\alpha_{\text {roof }}$ & $\alpha_{\text {if }}$ & $\alpha_{\text {fur }}$ \\
& $1.68 \mathrm{e}-7$ & $4.62 \mathrm{e}-7$ & $6.38 \mathrm{e}-7$ & $2.78 \mathrm{e}-8$ \\
& $5.83 \mathrm{e}-7$ & & & \\
\hline Main floor & $\alpha_{\text {walls }}$ & $\alpha_{\text {if }}$ & $\alpha_{\text {fur }}$ & \\
& $1.68 \mathrm{e}-7$ & $6.38 \mathrm{e}-7$ & $2.78 \mathrm{e}-8$ & \\
\hline Basement & $\alpha_{\text {walls }}$ & $\alpha_{\text {floor }}$ & $\alpha_{\text {insidewalls }}$ \\
& $8.67 \mathrm{e}-8$ & $4.92 \mathrm{e}-7$ & $1.52 \mathrm{e}-7$ \\
& $1.68 \mathrm{e}-7$ & & $8.67 \mathrm{e}-8$ \\
& & & $1.52 \mathrm{e}-7$ \\
& & & $1.52 \mathrm{e}-7$ \\
\hline Basement-1 & $\alpha_{\text {fur }}$ & & \\
& $2.78 \mathrm{e}-8$ & & \\
\hline Basement-2 & $\alpha_{\text {fur }}$ & & \\
& $2.78 \mathrm{e}-8$ & & \\
\hline Basement-3 & $\alpha_{\text {fur }}$ & & \\
& $2.78 \mathrm{e}-8$ & & \\
\hline Basement-4 & $\alpha_{\text {fur }}$ & & \\
& $2.78 \mathrm{e}-8$ & & \\
\hline
\end{tabular}

Table 6: Parameter specification in the multi-room model - Overall heat transfer co-efficient $\left[\mathrm{W} /\left(\mathrm{m}^{2} \mathrm{~K}\right)\right]$

\begin{tabular}{lllll}
\hline Attic & $\mathbf{U}_{\text {walls }}$ & $\mathbf{U}_{\text {roof }}$ & $\mathbf{U}_{\text {if }}$ & $\mathbf{U}_{\text {fur }}$ \\
& 0.2 & 0.28 & 0.1 & 1 \\
& 0.2 & & & \\
\hline Main floor & $\mathbf{U}_{\text {walls }}$ & $\mathbf{U}_{\text {if }}$ & $\mathbf{U}_{\text {fur }}$ & \\
& 0.1 & 0.1 & 1 & \\
\hline Basement & $\mathbf{U}_{\text {walls }}$ & $\mathbf{U}_{\text {floor }}$ & $\mathbf{U}_{\text {insidewalls }}$ \\
& 0.35 & 0.1 & 5 \\
& 0.35 & & 5 \\
& & & 0.1 \\
\hline Basement-1 & $\mathbf{U}_{\text {fur }}$ & & \\
& 0.2 & & \\
\hline Basement-2 & $\mathbf{U}_{\text {fur }}$ & & \\
& 0.2 & & \\
\hline Basement-3 & $\mathbf{U}_{\text {fur }}$ & & \\
& 0.01 & & \\
\hline Basement-4 & $\mathbf{U}_{\text {fur }}$ & & \\
& 4 & & \\
\hline
\end{tabular}

measurements. The model is fast compared to the reality, and this could be due to the underestimation of the thermal mass of the building. Further, in single-zone modeling, the whole building is simulated as one unit. However, predicting one temperature profile for a considerably large residential building with multiple floors is not straightforward. Buildings with multiple floors may have different heating requirements in each floor and hence exists several temperature setpoints based on the occupancy and other conditions. Therefore, it should be noted that representing the temperature of the whole building with one value may not be highly appreciated as it can lead to wrong control in specific areas with particular requirements.

Simulation of the test building using the multi-floor model provides reliable predictions compared to the single-zone model. Slight deviations of predicted and measured temperatures can be recognized. In the building, the attic has the highest temperature as it is influenced by high-temperature air currents flowing from the basement. Temperature prediction of the main floor is in good accordance with the measurements. However, there are some obvious deviations which could be owing to the wood firing that has not been introduced into the model. Basement simulations also follow the measurements with a small error.

Multi-room model predictions for the attic and the main floor are quite similar to the multi-floor model simulations and at some instants it resembles better predictions than the multi-floor model. The temperature predictions obtained for each room in the basement are not in good compliance with the measurements, especially in Basement-1 and Basement-3. However, the modeling of the storage rooms in the basement is not so significant compared to the hall, bathroom and sleeping rooms as they are not occupied. The reasons for deviations in the predictions and measurements could be due to either one or all matters addressed below.

- Poor modeling of internal heat transfer processes such as conduction through the inside walls.

- In the Basement-1, the hall has the largest area while sleeping rooms, bathroom and the entrance are relatively small. The hall and the bathroom are floor-heated by $550 \mathrm{~W}$ and heating is slow due to the concrete floor in the basement. Two sleeping rooms are heated by wall heaters of each $750 \mathrm{~W}$, and the heating process is fast. When the heating processes of different sources and different rates are coupled, the involvement of some waiting parameter may provide better estimations. In this study, there is no such parameter applied.

- Even though, the rooms are combined to simplify 
the model; it may complicate the behaviour of each room.

- As the developed multi-room model is a white box model, it is hard to predict the actual response of rooms without using some data based strategy.

All three models were calibrated by varying the most uncertain parameters such as heat transfer coefficients and thermal diffusivities. However, the manual calibration becomes time-consuming and also it does not provide good results when the models are getting complicated. One reason for the deviations in the predicted and measured temperature profiles is manual calibration. Hence, more reliable methods should be developed such as Kalman filtering.

As mentioned in the introduction section, the models are developed to study their feasibility in applying in heating time estimation of the building and temperature control applications. If the model can predict the heating time based on predicted weather conditions within a short period, it can be used to turn on and off the heaters at the correct time. This will help to save energy. Further, the accuracy of the model is important. The prediction times for each model discussed above are very short and wiithin 5 minutes interval (single-zone i multi-floor i multi-room) for 120 hours of simulation. All simulations were operated on a CORE i5 laptop computer having Windows 7 operating system and 8 GB memory. The prediction time, however, rises depending on the model complexity. Prediction accuracy of the temperature in multi-floor model is rather close to the real measurements which is satisfactory to utilize in a temperature control system. Further, the developed multi-floor model can be used to obtain a good estimation of the energy use of the building.

\section{Conclusion}

Physics-based building heating models have succeeded in the design, construction and operational activities in buildings. There are various types of physical models available in the literature, and it is a challenge to recognize the best fitting model to utilize in on-line control of buildings.

In the study, three MATLAB simulations based on three distinct models were performed for a multi-storey residential building having several rooms. Single-zone and multi-floor models are quite simple and easy to handle. However, the complexity of the multi-room model is determined by the number of rooms combined in each floor. All three models provide fast predictions. The single-zone model may be too simplistic for simulating multi-floor buildings. Based on the outcomes, it can be concluded that multi-floor model is the best choice to be used as a stable temperature predictor and as a good model for control purposes.

\section{Nomenclature}

The symbols used in the model is explained in Table 7.

\section{References}

Allard, F., Bienfait, D., Haghighat, F., Liebecq, G., Mass, K., Pelletret, R., Vandaele, L., and Walker, R. Air flow through large openings in buildings. Technical report, International Energy Agency, 1992.

Allard, F. and Utsumi, Y. Airflow through large openings. Energy and Buildings, 1992. 18(2):133 - 145. doi:10.1016/0378-7788(92)90042-F.

Brown, W. and Solvason, K. Natural convection through rectangular openings in partitions1. International Journal of Heat and Mass Transfer, 1962. 5(9):859 - 868. doi:10.1016/0017-9310(62)90184-9.

Desta, T. Z., Brecht, A. V., Quanten, S., Buggenhout, S. V., Meyers, J., Baelmans, M., and Berckmans, D. Modelling and control of heat transfer phenomena inside a ventilated air space. Energy and Buildings, 2005. 37(7):777 - 786 . doi:10.1016/j.enbuild.2004.10.006.

EBPD. On the energy performance of buildings. Official Journal of European Union, Directive 2010/31/EU of the European Parliament and of the council, 2010. pages 13-34.

EU. Energy efficiency trends in the eu. Technical report, European Commission, 2013.

Foucquier, A., Robert, S., Suard, F., Stphan, L., and Jay, A. State of the art in building modelling and energy performances prediction: A review. Renewable and Sustainable Energy Reviews, 2013. 23:272 - 288. doi:10.1016/j.rser.2013.03.004.

IEA. Energy policies for iea countries, norway. Technical report, IEA, 2011.

Khoury, Z. A., Riederer, P., Couillaud, N., Simon, J., and Raguin, M. A multizone building model for matlab/simulink environment. In Ninth International IBPSA Conference2005: Montreal, Canada. 2005.

Kramer, R., van Schijndel, J., and Schellen, H. Simplified thermal and hygric building models: A literature review. Frontiers of Architectural Research, 2012. 1(4):318 - 325. doi:10.1016/j.foar.2012.09.001. 
Table 7: Nomenclature

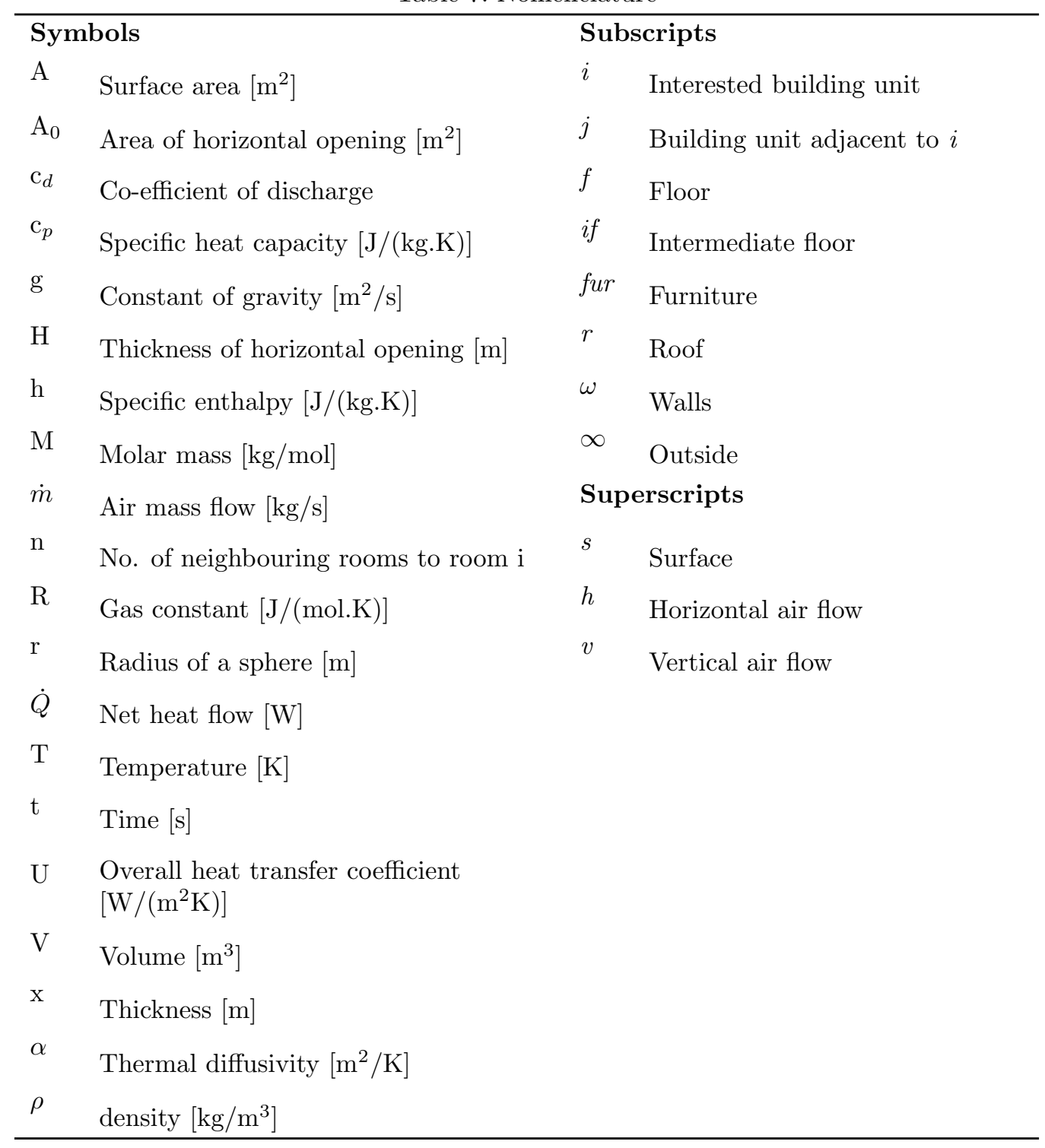


Kusuda, T. Fundamentals of building heat transfer. Journal of Research of the National Bureau of Standards, 1977. 82(2):97-106.

Lin, Y., Middelkoop, T., and Barooah, P. Issues in identification of control-oriented thermal models of zones in multi-zone buildings. In Decision and Control (CDC), 2012 IEEE 51st Annual Conference on. pages 6932-6937, 2012. doi:10.1109/CDC.2012.6425958.

Lu, X., Clements-Croome, D., and Viljanen, M. Past, present and future mathematical models for buildings. Intelligent Buildings International, 2009. 1(2):131-141. doi:10.3763/inbi.2009.0024.

Lu, X., Lu, T., Kibert, C. J., and Viljanen, M. A novel dynamic modeling approach for predicting building energy performance. Applied Energy, 2014. 114:91 103. doi:10.1016/j.apenergy.2013.08.093.

Mendes, N., Oliveira, G. H. C., Arajo, H. X., and Coelho, L. S. A matlab based simulation tool for building thermal performance analysis. In Eighth International IBPSA Conference. 2003. Eindhoven, Netherlands. 2003.

Paulou, J., Lonsdale, J., Jamieson, M., Neuweg, I., Trucco, P., Maio, P., Blom, M., and Warringa, G. Financing the energy renovation of buildings with cohesion policy funding. Technical report, European Commission, 2014.

Peppes, A., Santamouris, M., and Asimakopoulos, D. Experimental and numerical study of buoyancydriven stairwell flow in a three storey building. Building and Environment, 2002. 37(5):497 - 506. doi:10.1016/S0360-1323(01)00060-9.

Perera, D. W. U., Pfeiffer, C., and Skeie, N.-O. Modelling the heat dynamics of a residential building unit: Application to norwegian buildings. Modeling, Identification and Control, 2014a. 35(1):43-57. doi:10.4173/mic.2014.1.4.

Perera, W., Pfeiffer, C. F., and Skeie, N.-O. Modeling and simulation of multi-zone buildings for better control. In 55th Conference on Simulation and Modelling, Aalborg, Denmark: Linkping University Electronic Press. 2014b.

Riffat, S. Algorithms for airflows through large internal and external openings. Applied Energy, 1991. 40(3):171 - 188. doi:10.1016/0306-2619(91)90056-4.

Rosa, M. D., Bianco, V., Scarpa, F., and Tagliafico, L. A. Heating and cooling building energy demand evaluation; a simplified model and a modified degree days approach. Applied Energy, 2014. 128:217 - 229. doi:10.1016/j.apenergy.2014.04.067.

Spindler, H. C. and Norford, L. K. Naturally ventilated and mixed-mode buildingspart i: Thermal modeling. Building and Environment, 2009. 44(4):736 - 749. doi:10.1016/j.buildenv.2008.05.019.

Virk, G., Cheung, J., and Loveday, D. The development of adaptive control techniques for bems. In Control 1991. Control '91., International Conference on. pages 329-334 vol.1, 1991.

Yao, Y., Yang, K., Huang, M., and Wang, L. A statespace model for dynamic response of indoor air temperature and humidity. Building and Environment, 2013. 64:26 - 37. doi:10.1016/j.buildenv.2013.03.009.

Zhao, H. and Magouls, F. A review on the prediction of building energy consumption. Renewable and Sustainable Energy Reviews, 2012. 16(6):3586 - 3592. doi:10.1016/j.rser.2012.02.049. 